\title{
The role of genetic in delinquency of women with emphasis of cinderella theory
}

\begin{abstract}
Victim and offender manufacturer of Criminology triangle to date have been the focus of many criminologists But in the meantime the offender can be considered the most important sides of Criminology. There is no doubt that forensic biology for runners examination of crime Biologists sometimes extreme approach and adherence to the theory of biological determinism with respect to the criminal brigade and sometimes as distinct from the nonoffending and delinquency people with balance oriented approach, denied the existence of chromosomes algebra concept of crime and criminal and inspired by biology, social, criminal and deviant behavior tendencies of autonomous but has been considered Biology perspective view compliance with boys and girls can be said that the specific characteristics of their own personality. Each according to gender and dragged characterized by various offenses Trends and led to some girls and young women to delinquency and criminal acts, examples of anomalies that Compared with the traditional society of the past decades and centuries, with significant growth coupled with a need to review it in criminology theories are inevitable Cinderella theory as a new theory admits that girls ensconced in their dreams and fantasies in real life Cinderella plays their own role. Thus, self-confidence and selfesteem so their delinquent girls lose and this causes it gets the handle to resign. Or to vent anger and feel the excitement and the offenders themselves become social. The results show that the claims about the role of genetics in the commission of the crime, the more need careful studies and findings and yet not be denied the role of genetics in the field of criminal behavior. But on the other hand is no evidence to accept the role of this factor alone is not achieved.
\end{abstract}

Keywords: cinderella, genes, genetics of behavior, delinquency women
Volume 4 Issue 5 - 2017

\author{
Fatemeh Ahadi,' Mahdi Omani \\ 'Assistant Professor, Department of Law, Islamic Azad University, \\ Iran \\ ${ }^{2}$ Department of Law, Islamic Azad University, Iran
}

Correspondence: Fatemeh Ahadi, Assistant Professor,

Department of Law, Maragheh Branch, Islamic Azad University, Maragheh, Iran, Email fatemeh.ahadi I394@gmail.com

Received: April 25, 2016 | Published: May 08, 2016

\section{Introduction}

In the twentieth century and after World War II due to the complexity of social relations and industrialization of societies and the subsequent loosening of emotional relationships governing the family, excessive migration to the big cities and the increasing marginalization, the context appropriate to extend deviations the social, as a result, many people for various reasons were committing crimes. This time worrying gets more we find that the adolescents the active force and the future construction of society and in the capital of the future of any society are considered to be a significant percentage of these offenders make up. ${ }^{1}$ Genes important in determining behavior, since the beginning of the twentieth century eugenics movement has been a lively discussion Hazrhmvarh time. ${ }^{2}$ DNA molecules important role in the physiological, morphological traits and diseases in humans. As information about the physical attributes such as height, hair color, eye color, etc. in the DNA molecule that is inherent to every human being inherited from parents. Studies and new research genetics have shown that genes not only of physical properties involved but also in behavior such as agitation ability, irritability, sudden, radical act, sensation seeking, adventure and mental disorders such as schizophrenia and depression Two polar decisive role. ${ }^{3}$ Tabula rasa as one of the most famous hypothesis that human activity has described other is not acceptable and researchers are trying to discover the mechanisms and alternative hypothesis that the human brain to understand the complex activities. Many investigations have shown that the type and quality of the DNA molecule basis physiological properties, and the appearance of diseases in humans. In the past decade, particularly at communication science of behavioral genetics and the activity of genes and their effects on human behavior and achieved some success in many diseases. But the important question for many of the scholars of the humanities in the past few decades has been to what extent genes in behavior and personality involved and whether genes can be mainly direct and indirect origin of delinquency among adolescent girls, or not?

\section{Women in biological criminology theories comments}

One of the first research efforts have been made to explain criminal behavior of women, by Cesare Lombroso has been made. He and William Ferrero in 1895, wrote a book entitled Women offenders; today it is considered one of the classics in criminology. Lombroso that advocates social Darwinism was announced that the criminal behavior of women compared with men less because the maternal instinct in women due to physical weakness and mental cruelty and the less commit crimes; He believes that, in fact, the leading cause of female crime "sexual issues" is. In his view, beautiful young women, especially prostitutes, one of the major causes of female crime is low, official statistics; because they incite lust with men, leading to ignore the sins and crimes they provide. Most theories of crime for many years exclusively on women's sexual anatomy and especially those focused areas (Siegel and Sinai, 2000). Thomas also like Lombroso women from sexual delinquency was examined, in awkward Girls (1928) has turned its attention to female prisoners and found that most of them were suffering from sexually transmitted diseases. So, that to prevent the outbreak and spread of the disease at the time (World War I) were imprisoned. Accordingly, it is not surprising that Thomas 
almost all offenders' women from sexual problems caused by them. In his view, women often use sex as "capital" to obtain goods like clothes, money, and so they use. Although he did not condemn the deal, but the social system to the criticism that his once prosperous women to sell (for marriage). While poor women are forced to be less than compelling (entertainment, leisure, love, and perhaps receiving gifts). ${ }^{4}$ Catherine Dalton (1961) pointed out that because of some crimes women can be related to hormonal changes during menstruation (premenstrual tension or PMT) searched. Abbott, 1382 and Pollack, 1950 also emphasized the biological model women he has tried to explain deviations. According to official statistics in their research they found that women were significantly less compared to men committed crimes; this is due to the importance of biological and psychosocial factors and cunning women knew. Thus, according to the researchers, delinquency women of "Sex" or "relationship" to "crimes" Therefore, in this study, aspects of psychological, familial and cultural rights of women and girls offender is ignored. ${ }^{4}$

\section{Behavioral genetic influences on personality}

Behavioral genetics for his study of two related trends uses: Molecular Genetics, Quantitative Genetics. Molecular genetics to examine the effects of specific genes in the DNA is final. Quantitative Genetics is a theory about the effect of polygenic, along with the environmental distribution leads to distribution of quantitative phenotypes. Quantitative genetic methods, such as methods for the analysis of human twins and adopted children, the role of genetics and environment on phenotype distribution in a population is estimated. Behavioral genetics has gained much success in their study. Study the effect of genes and environment in the emergence of many examples of behaviors such as antisocial behavior, intelligence, willingness to violence and many other behaviors can be outlined. ${ }^{6}$ About the role of genetics in behavior and personality characteristics. Many studies have been conducted important studies are briefly mentioned here. The exciting personality traits in humans has been shown that different people have different exciting tasks resort and this intrinsic motivation and structure of the brain in each individual. Traits of agitation, irritability, sudden, extreme action and speech that action, sensation seeking, disorder, adventure and feel free from all shackles of the features of the people seeking acts are harmful and dangerous. The feel of modernity with a high degree of human molecules in a brain chemical called dopamine is released. Not only can people have different numbers of molecules there are multiple receptor molecule dopamine, but its effectiveness is different for each person. ${ }^{3}$ Another feature of behavior that is related to the feeling of excitement, avoiding the damage. The sense of avoiding damage to one of the most basic, most stable and most diverse dimensions of human psychology. It felt even before birth (during fetal development) appears as a rapid heart rate in adults leads to the formation of the personality and causes restlessness and inflammation. Various studies have shown that the roots of embarrassment and shyness examples of behavioral characteristics are avoiding damage in one part of the brain called the amygdala.

In addition, multiple tests are multiple genes and proteins in the brain to confirm that the personality trait makes it possible to avoid damage. Of course, individuals in a population with a genetic predisposition are different in this regard. Nervous and aggressive behavior, behavior that almost everyone has experienced it, but in some societies is most prevalent. Although each individual life gets angry and this behavior depends on the special circumstances of one's life, But persistent violence and anger continues in an individual, the potential of the negative outlook of many people in the community will follow. Aggressive and negative behavior to avoid damage and feel a sense of fear and anxiety related. Studies on people who have been adopted and away from parents themselves have grown, indicating that if the child's father or mother or both, bad genes inherited, in adulthood are violent and aggressive behavior. The results of this study indicate that it is something that is inherited, bad behavior or violence, but genetic susceptibility to factors that are present in the environment. But generally favorable genetic background and exposure to environments that promote violence and aggression, it causes people to show more aggressive behavior. Addiction vulnerability personality and behavior can be seen in many people. Addiction to drugs, alcohol, cigarettes and substances such as chocolate, including materials that people need to fit the cover on the negative feelings they have used. Studies have shown that in general, the brain susceptible to becoming addicted, but some of the brain due to genetic background, are more susceptible. In studies of identical twins have shown that this type of addiction is much more twins than fraternal twins. For example, it is estimated that addiction has inherited Sygar- of about $48-28$ percent. In studies on sexual attraction between men and women and the desire to have sex, researchers have concluded that the sexual instinct within humans, a genetic resource comes and genes in the emergence of feelings of sexual attractiveness of humans they have a central role. About the characteristics of obesity, intelligence and aging are also many studies and they confirm this fact that genetics play a significant role in the amount and degree of each of these personality characteristics and behavior in humans.

The role of genes in mental illness during the past decade has been studied using different methods. Many studies have been conducted on identical twins and some studies of ordinary families and those who have been adopted, has been made. It seems that the disease of schizophrenia, Avtyzm-Adha and inheritance of dyslexia is higher than $70 \%$ have. ${ }^{7}$ Hulin in 1992, raised two questions in this regard:

\section{Is there evidence for genetic influences on criminal behavior?}

\section{If such an effect exists, how it works and what is the role?}

The first question using the tools of genetic research in psychology (study of family history of twins and children) checked. In the studies, family history, to investigate the criminal behavior in families. Bsurn and the West in 1982, compared with boy's criminal and non-criminal fathers, found that 13 percent of non-criminal fathers, sons, fathers and 40 percent of male offenders, are judicial sentence. At first glance it is clear that the role of genetics in the field is important. In contrast, poverty can be considered as both father and son, is a collaborative environment, Learn criminal behavior in the family, is compatible with the third hypothesis. In other words, a shared environment, the behavior is similar. If you accept or reject each, there will be a lot of unanswered questions. In the study of twins, like an egg twins (MZ) and Dvtkhmky (DZ) from the perspective of specific behaviors were investigated. Communication studies in identical twins is higher for criminals who can be the role of genetics in this behavior. Another study showed that rates along with the same criminal behavior, the twins, one egg and two egg $35 \%, 13 \%$.But because of this association is not too high, it can be concluded that if the gene is involved in the field, its effect is small. But because of the lack of reviews and the number of twins studied to determine the exact one hand, and dizygotic twins a continuing studies. ${ }^{8}$ Adoption studies have shown that children with biological parents show more similarities. 
Although the statistics do not fully approved it. ${ }^{9}$ On the other hand, may dizygotic twins, a girl and a boy. In this case, such a study is not independent of the gender factor. In the science of criminology, criminal behaviors affect genes from two directions: first, through the transfer of properties and biological properties known as "heritability and crime" will be discussed. Second through changes that may occur in the following "genetic disorders" is considered the most important cases of disorder or XXY is because YYX. ${ }^{10}$ Sex by chromosomal pattern XX (female) or XY (male) form. Chromosome Y, male gender plays a role in creating. The presence of a $\mathrm{Y}$ chromosome added, XYY, creating a special feature entitled "Superman" is. People $\mathrm{XYY}$, in addition to difficulties in learning and IQ are more violent and criminal behavior than normal males of the show. Yet people in psychiatric hospitals and prisons, have been reported. In the 1960s and 1970s showed that men who had an extra Y chromosome, and XYY syndrome are called, are at higher risk for committing violence. Researchers in the nineteenth and twentieth centuries, showed that low intelligence could be responsible for some criminal acts. However, some problems related to intelligence, genetic origin. According to a report in the science journal, published in 1993, describes a family of Dutch were several men, the syndrome that includes mental retardation and abnormal behavior was, were affected. These people lack the enzyme monoamine oxidase a key neurotransmitter in the brain that breaks down a lot. Genetic analysis showed that men with mutation in MAOA gene on the $\mathrm{X}$ chromosome have. ${ }^{11}$

\section{Heritability}

Inheritance as a phenomenon reflecting the position of ancient history and ancient philosophers of Greece and thoughts religions, but all of it, it became clear that Gary Gregory Mendel's laws of inheritance discovered and his research led to the later position. Genetic characteristics of chromosomes in the cell nucleus genes revealed the role of heredity in social and individual behaviors to be more specific. Development genetics also confirms the theories of heredity. ${ }^{12}$ In general, the first stage of the study the role of genes in crime and delinquency has emphasized, genealogy or according to the origin and ancestry of the individual and family background. He had to determine whether the American family of History of criminal behavior or not. Later, chromosomal abnormalities and neurological factors were studied and the relationship between the findings of these studies were prepared individuals to commit crime. Biologists new study of twins next attempt to prove the role of heredity in general and specifically the role of genes in the emergence of deviant behavior. ${ }^{1}$ Franz Kalman (1956), one of the scientists who concluded percent of people with mental illness such as schizophrenia, dementia, manicdepressive and manic aging in identical twins than the incidence of this disease in twins, non-identical or brothers and sisters normal way is undeniably more. He accordingly emphasized the impact of genetics in causing mental illness.

Thompson (1975) also believed that genetic factors are partly responsible provider of mental illness, but the action and transmission of hereditary characteristics or backgrounds and ways of expression and it is not clear. In his later years, some scientists tried on the basis of precise research methods more scientific and controlled them was the importance of inheritance in their behavior. For example, Gatsmn and Shields (1976) and Rosenthal (1979) conducted research methodologies that are much more accurate and more scientific research was Thompson. They concluded that between genetics and abnormal behavior, correlated. ${ }^{13}$ So we can say that genetic characteristics and genetic factors that are almost the first criminologists have studied its role in the development of delinquency. Their scientific evaluation of these factors, the forensic biology and forensic also got help was based on forensic biology. About genetics and genetic extremes has been made. A group of scientists Foundation, delinquency, and crime authenticity of inheritance have been made to introduce laws of inheritance. According to them, genes Offenders dominant are the way sex parents offenders with children moves and children grudgingly itself, the phenomenon of compulsive and heritage imposed from the moment of birth with them and because of the emergence of human behavior in the wild, they regress found. And the evolution of open stand (Alizadeh, 1382). Unlike the theorists, Enrico Ferri believed that between heredity and delinquency is no causal relationship there is no direct and delinquency in the nature of the individual to his descendants moved because the ethics and behavior of an acquired (Rahimnejad, 1380 ). However, in many cases, studies show that diseases of parents, such as syphilis, alcoholism, drug addiction and mental disorders, the gene productive characteristics of their children, the effects of the leaves that may be fertile ground providing for conflict and deviant behavior. As the children of alcoholics, children with antisocial personality or temperament much has been wrong. ${ }^{14}$ On the other hand, violence, aggression and aggressive behavior have a genetic origin. Some people are born with neural connections shorter and more possibility there is that they are aggressive and angry. The question of whether genes play a role in violent behavior and associated crime or not? is controversial.

But even with the most talked about opposite those who believe only bad environment, bad man produces, cannot deny a simple biological fact. The most important factor in determining whether a person has a violent or aggressive behavior, called by chromosome $(\mathrm{Y})$ is done and the chromosome determines male gender. In this regard, the statistical evidence is excessive. For example, according to the Department of Justice United States of America, men compared to women more than 5 times in attacking other people. And 10 times longer than for homicide and 86 times more likely to be accused of sexual assault. On the other hand, throughout history, wars have been started by men in most cases. ${ }^{7}$ While the crimes and adherence to social norms among men than women are. Therefore, since in most studies, abnormal behaviors and norm transgressions of men frequently and more severely than women are, hence the changing role of gender in determining abnormalities important social considered (firoozjaeian, 1387). It is also not without benefit, but some studies have shown. In heritance of antisocial and aggressive behavior in women significantly more than men is its inheritance. ${ }^{15}$ However, studies show that as the man financially heir to his relatives may be in terms of individual inherits talent, temperament and character of good and evil ancestors and their ancestors from the inheritance passed to him there are. ${ }^{16}$ However, research conducted and the results obtained by biology and the humanities in recent years about the extent and the effects of genetics on behavior suggests that mental illness directly through the genes and heredity transfer not, but genes are the only factor that set the stage for illness to a person to inherit it. If the reason for the child's genes to be transferred and in the environment also have a pathogenic condition, then in person, the symptoms of mental illness such as schizophrenia or affective psychosis will appear. So even if a person is in the field of inherited, but environmental conditions are not favorable for the disease, a person will not be affected. In this model, there are some physical ailments. For example, a building may be physically weak and powerless against tuberculosis is a inherit. If the person infected with tuberculosis should be exposed to the risk he gets a lot of patients; But if a person has inherited physical structure 
is resistant tuberculosis or environments contaminated, is not he, will not be affected. The same situation is true in the case of mental illness. This means that if a person has inherited readiness to develop certain diseases and have the same terms of living space, especially in childhood and adolescence undesirable and pathogenic, then the chance of his mental disorders will most. ${ }^{13}$

\section{The role of gene fight}

Since the early 1990 s, scientist's probable relationship between anti-social behavior and failure of a particular gene (gene fight) spoke. This defect occurs in a gene that is responsible for creating an enzyme called monoamine oxidase (Mao-A) has claimed. It is said that negligence in this gene cause too much damage a number of chemicals in the brain. These substances, one of which is to create serotonin can help calm human being. With too much damage these substances, the risk of sudden and violent emotional reactions to stimuli such as fear or threat is over. Scientists why this particular gene-fighting gene was named, but recent research (2009) Kevin Beaver writes: "For the first time we managed to communicate clear and between genes (Mao-A) and lifestyle choices associated with violence find. Beaver and colleagues found that men with the little activity of the gene (Mao-A) are 2 times more likely than other men to groups and categories of assault to come from among those in the group are members, they work (Mao-a) are 4 times lower than your teammates use of weapons (Bakhit, 1388).

\section{The adoption}

Adoption process is called where a child by one or more adults who were not his biological parents but legally considered to be his parents, the family will be accepted. ${ }^{17}$ Adoption studies on the role of genetic factors in criminal behavior was another attempt by the researchers. The adoption, There exists a method for genetic evaluation whereby the Review of adopted children from an early age, to seek to achieve an appropriate response to the issue of whether foster children resemble their parents are? (Of genes) or secondary to their parents look like? (Environmental Excellence). The results of this research in particular confirms that the country of Sweden and Denmark Genes in female children are more important, which means that the majority of women offenders have been tested in a limited ages. People inherit genes that people are partially exposed to antisocial and criminal behavior puts this issue is directly dependent on the environment in which one is raised. Consequently, the aforementioned field research confirms that the risk of becoming delinquent adoption if the parents are the main offenders were 12 percent and 7 percent if the parents are delinquent secondary. But if parents are the primary and secondary they are all criminals, this risk increases to $40 \%{ }^{18}$ In another study in order to control the environment, examples of adopted children selected for the study and birth in the place that they not only her biological parents did not know, but most of them even in the first years of life, not knowing that are adopted. The study, conducted Sarnf Mdnyk and his colleagues on the Danish foster children and other studies show that genetic factors play a role in the commission of criminal behavior and should ignore these factors. ${ }^{1}$ Various studies have shown that emotional and behavioral problems such as aggressive behavior, theft and learning problems among children who have been adopted more than other children. ${ }^{17}$

\section{Citizen's role}

Another aspect of adoption, siblings study "hereditary" and "environment" as well as parents. Siblings "inherited" real siblings are separated early in life and raised in different families. Siblings "peripheral" Children are not related to the family and early life have been adopted in a selected family. In this particular attribute, according to the method similar to the method similar traits between adoptees and siblings to study "hereditary" and "environmental" he explains. If a particular attribute adopted with siblings "inherited" have in common, then we can conclude that inheritance of these traits have a more significant impact. Conversely, if adopted in a particular attribute Siblings "environment" in common, it can be concluded that environmental factors in its rise has been more dominant trait. ${ }^{5}$

\section{The role of identical twins}

In terms twins from a single fertilized egg emerges, as "identical twins or identical" are called. The incidence of identical twins of 3 to 4 per 1,000 births. Almost two-thirds of twins, dizygotic or nonidentical and the incidence of 7 to 11 cases per 1,000 live births, the maternal age increases, it becomes more likely. For example, Rashtn and colleagues (1986) examined the aggression on 573 pairs of twins. The results showed a correlation between identical twins and dizygotic twins was the lack of correlation between. According to them, the results indicate a strong genetic influence. However, evidence suggests that genetic factors in determining individual differences in sexual orientation (homosexuality) play an important role and schizophrenia often occurs in identical twins. ${ }^{15}$

\section{The role of blood groups}

One of the causes of biological and genetic influence in the development of the human personality, blood type, which over the past few decades, the researchers made the hypothesis that the character and blood relationship exists, the source of lot of research has been conflicting results various countries have been obtained. ${ }^{16}$ In this regard, a number of biologists and pathologists believed that some of the moral and psychological characteristics of human beings through genetic and can be transmitted by blood. As a result of extensive research began long ago that significant results are achieved. Leicester research results showed that a higher proportion of people with blood group $(\mathrm{O})$ have rates of suicide cases are less and less from other nations are anxious. The results of other studies in this area also suggests that people with blood group (A) more than other blood groups OCD patients and people with blood group $(\mathrm{O})$ more than other disorders Phobia are experiencing.

\section{The role of chromosomal abnormalities}

Chromosomes from two Greek words chroma (Croma) means "color" and (Soma), meaning "flesh" taken together, the "Rainbow Body" is called. This appellation is due to the ease of staining chromosomes in microscopic tests (NajafiTavana, 1385). Units of heredity from parents to children arrive and are transmitted to the next generation by the same chromosomes in the nucleus of every cell in the body structures are transmitted. Most human cells have 46 chromosomes. Each person has 23 chromosomes from the sperm of the father when fertilization (sperm) and takes 23 chromosomes in each cell division, can be reproduced. In each chromosome inheritance of single gene called there. Each gene is part of the DNA molecule or deoxyribonucleic acid (DNA) is the main carrier of heritable information. Commands encoded genes to cells and lead them to a certain function. About a thousand genes in the human chromosome or even more there. Due to the large number of genes, there is very little probability that two individuals, although some parents were born have equal inheritance. The only exception in this case, is identical twins because of a single fertilized egg arise, their genes are absolutely identical. ${ }^{19}$ In terms of biology, chromosome (X) for 
women and chromosome (Y) for men. Chromosomal abnormalities are not men, they shaped chromosomes (XY) and female chromosome, the chromosome from their $(\mathrm{XX})$ is. ${ }^{1}$ Some scientists believe that probably the most important role of chromosomes (Y) command to make testosterone. The hormone that makes male half of the human population. Part of the reason is that testosterone by the testes and the body is released, its value at the time of puberty in males with speed rises (the same time to increase the degree of violence) and older, slowly decreases. So the violence is also low in person. But this theory has been delivered.

\section{Brain structures}

This section focuses on the parts of the brain front. In this regard the differences between the two hemispheres of the brain will be discussed. The reason for it is closer to the brain caused permanent damage serious offenders is an important part of life in the brain and lead to unethical behavior, irritability, impulsive and anti-social acts.

\section{The left hemisphere of the brain}

Dysfunction of the left hemisphere, compelling factor associated with violence and criminal behavior in psychiatric patients, sex offenders and others with a variety of methods has been proven. The volume korpors in the brain is, the less people respond to stress and symptoms of mental illness in them is greater. The experiments showed a balance of activities that may Mghrast hemisphere of individuals with regard to delinquency, is unusual. On the other hand there is evidence that, according to them, the brains of some Azbzhkaran of the function and structure of the brains of people with non-delinquent, are different. This is especially the case of persistent offenders, motivated and aggressive, striking. ${ }^{2}$

\section{Brain evolution}

Antisocial behavior, something not unusual, so it is unlikely that most of the problems such as tubers, defective genes or injury occur. During the past 50 years, researchers have begun to understand the normal process by which the brain in response to the environment evolves. This development continued in the first 20 years of our lives, usually after age 30 also continues. Abdomen mother fetus than the mother is sensitive to the environment. It is typical in this regard, many people thought. At the end of the Second World War, famine arose in the Netherlands, to the extent that people are forced to eat things such as onions and tulips, grass and even had mice. Meanwhile pregnant women in the third trimester, low birth weight babies were born. But the women in the first trimester of pregnancy had babies weighing more than average were born. This phenomenon was unexpected and showed the power of the environment in changing biology. On the other hand, in humans, babies in the womb are exposed to alcohol or drugs, they may evolve incomplete to exhibit at such a baby syndrome fetal alcohol and percent, according to research carried out an in 500 in the whole world. ${ }^{20-25}$

\section{Conclusion and recommendations}

There are several reasons for criminal behavior. Studies the role of genetics in order to achieve this, by exploring their family history, studies of twins and adopted children is possible. The results of these studies, due to the interaction of genetics and environment, and also in their diversity, cannot be verified in practice as well. In modern behavioral genetics, the study of the relationship between criminal behavior and genetics with genetics, endocrinology, chromosomes, blood type and the argument that follows, organs, nervous system determines human behavior. And we learn how the nervous system controls behavior. Since the formation and function of the nervous system related to genetic inheritance is, therefore, possible, some behaviors resulting from a number of genes, is. In this context, several hypotheses have been proposed:

a. Any special treatment, may express different genes (polygenic) is affected.

b. Genes interact with the environment. Different behaviors by stimulating the appropriate operating potential become real.

c. Proof of the crime, caused by a faulty genetic inheritance does not exist.

In other words, genes are not the cause of crime, but under environmental influences, some violent behaviors increase crime.

\section{Acknowledgments}

None.

\section{Conflicts of interest}

The author declares there are no conflicts of interest.

\section{References}

1. Ahmadi H. Sociology of deviance. Organization of Study and Compilation of Humanities Books universities, Iran. 1385.

2. Darvish AR. Cash Cinderella structure theory of criminology, justice, hope. Law Quarterly. 1394;(1):135-141.

3. Ardakani MA. Behavioral genetics and culture. Journal of Medical Ethics. 1388;3(7):65-85.

4. Chesny L, Randall GS. Girls delinquency and Juvenile Justice. Willey Blackwell, USA. 1977;1-360.

5. DeFries JC, McGuffin P, McClearn GE, et al. Behavioral Genetics. $4^{\text {th }}$ edn. WH Freeman \& Co. USA. 2000.

6. Ancient B. Family Pathology. Journal of educational research. 1387;(3).

7. Copeland P. The role of genes in the formation of personality, Interpreter, Iran. 1382.

8. Appelbaum PS. Behavioral genetics and the punishment of crime. Psychiatr Serv. 2005;56(1):25-27.

9. Moradi IQ, Soraya MG. The role of genetics in delinquency. Proceedings of the 4th International Conference on Law, Ahwaz Islamic Azad University of Ahvaz, Iran. 1394.

10. Steven B. Criminology a sociological understanding. $4^{\text {th }}$ edn. Pearson Prentice Hall. USA. 2009;1-656.

11. Gosavi SR, Gajbe UL, Meshram SW, et al. Cytogenetic study in criminals (Murderers): Role of XYY chromosome in Criminality. Journal of Clinical and Diagnostic Research. 2009;(3):1911-1914.

12. Nurbaha R. General Criminal Law. Dadafryn publishing, Iran. 1386.

13. Shamloo S. Schools and theories in personality psychology. Growth, Iran. 1382.

14. Hidayatullah S. Forensic psychology. $7^{\text {th }}$ edn. Sounds of Light, Iran. 1386.

15. Shamsesfand AA. The jail population, the Prisons and Security and Corrective Measures. The way to training, Iran. 1384. 
16. Shambayati H. Actions by environmental containment strategies towards a crime. Free legal research publication . 1385;(19):80-119.

17. Harold K, Benjamin S. Summary of psychiatry (2). $10^{\text {th }}$ edn. City water, Iran. 1379 .

18. Bernstein PL. Against the Gods: The Remarkable Story of Risk. Wiley, USA. 1996;1-375.

19. Atkinson R, Rychardsy A, Wood SE, et al. Hylgard the field of psychology. $10^{\text {th }}$ edn. Growth, Iran. 1385.

20. Ltavyla E. Psychology judicial Who Proto-Mahdi. Majd, Iran. 1374.
21. Akrami, SM, Scholastic MH, Reihani F, et al. Genetic or environmental, which will determine our future? Journal of Bioethics. 1391;(4):181-194.

22. Rouzbeh. Gene discovery violence. Health Gazette. 1388;(228):1-6.

23. Mohammad K. Social pathology of the disease (I). Publication of sociologists, Iran. 1391.

24. Anthony G. Sociology. Reed Publishing, Iran. 1387 .

25. Nussbaum M. Women's capabilities and social justice. Journal of Human Development. 2000;1(2):219-247. 